barriers to ongoing testing within primary care. A Testing Month allows for a range of targeted initiatives but is short enough to maintain momentum. It is a model that translates easily to other smaller jurisdictions and supports relationships between key stakeholders.

Disclosure of interest No commercial contributions were received.

\section{P13.09 EVALUATION OF A PILOT TO IMPROVE PRIMARY CARE SEXUAL HEALTH SERVICES IN ENGLAND: ANALYSIS OF CHLAMYDIA TESTING AND DIAGNOSIS RATE CHANGES}

${ }^{1} \mathrm{~K}$ Town*, ${ }^{2} \mathrm{EJ}$ Ricketts, ${ }^{1} \mathrm{~T}$ Hartney, ${ }^{1} \mathrm{~A}$ Nardone, ${ }^{1} \mathrm{KA}$ Folkard, ${ }^{2} \mathrm{C}$ Rugman, ${ }^{2} \mathrm{~N}$ Ockendon, ${ }^{3} \mathrm{~A}$ Charlett, ${ }^{2} \mathrm{CAM}$ McNulty, ${ }^{1} \mathrm{JK}$ Dunbar. ${ }^{1}$ HIVISTI Department, Centre for Infectious Disease Control and Surveillance, Public Health England, London, UK; ${ }^{2}$ Public Health England Primary Care Unit, Microbiology Department, Gloucester, UK; ${ }^{3}$ Modelling and Economics Department, Public Health England, London, UK

\subsection{6/sextrans-2015-052270.507}

Introduction Provision of sexual health services in primary care is necessary to reduce STIs, such as chlamydia. We piloted an educational training programme, based on the theory of planned behaviour, for general practice staff with the aim of increasing chlamydia and HIV testing, and provision of condoms and contraceptive information (3Cs and HIV).

Methods The pilot was delivered with a step wedge design over three phases. Chlamydia testing and diagnosis rates pre and post-training were compared separately for men and women using a multivariable negative binomial regression model with general practice fitted as a random effect. Month of test and practice population size were adjusted for and an interaction between the intervention and area of implementation fitted.

Results 460 general practices agreed to participate in the pilot. These conducted 2448 tests across the pre and post intervention period. Intention to treat analysis showed decreased median test and diagnoses per month post-intervention (2.68 vs 2.67 ; 0.14 vs 0.13 respectively). The multivariable regression analysis did not find a significant change in testing or diagnoses of men. There was a significant increase in testing (IRR 1.15 CI 1.011.31) of women but no change in diagnoses (IRR 0.98 CI 0.84 1.18). Interaction between the intervention and area of implementation was found in both testing rate models for women. Conclusion This large national pilot found that educational support sessions slightly increased chlamydia testing in women within general practices after they received the $3 \mathrm{Cs}$ and HIV training but not diagnoses. The area of implementation had an impact on the programme's effect, so further exploration of the factors that contribute to this increase is required.

Disclosure of interest statement Public Health England is funded by the UK Department of Health.

\section{P13.10 CLUB DRUG USE, SEXUAL BEHAVIOUR AND STI PREVALENCE IN SEXUAL HEALTH CLINIC ATTENDEES IN A UK CITY}

${ }^{1} \mathrm{NE}$ Ekong, ${ }^{2} \mathrm{MD}$ Portman, ${ }^{1} \mathrm{~J}$ Murira, ${ }^{3} \mathrm{~J}$ Roche, ${ }^{4} \mathrm{P}$ Charles, ${ }^{1} \mathrm{JD}$ Wilson*. 'Leeds Teaching Hospitals NHS Trust; ${ }^{2}$ Homerton University NHS Foundation Trust; ${ }^{3}$ Black Country Partnership NHS Foundation Trust; ${ }^{4}$ Leeds and York Partnership NHS Foundation Trust

10.1136/sextrans-2015-052270.508
Introduction Club drug (CD) use is increasing, but use in nonswinging heterosexuals and associations with sexual behaviour and STI prevalence is undocumented worldwide.

Methods Sexual health clinic attendees aged $\geq 16$ years were invited to complete a questionnaire on sexual behaviour and drug use for two weeks per quarter in 2013-14. CD use was compared with age, sexuality, sexual behaviour and STI rates to determine any associations.

Results 2332 questionnaires were analysed; mean age 27 (1681 ) years; $52 \%$ male; $75 \%$ white British; $82.6 \%$ heterosexual; $11 \%$ MSM.

Lifetime CD use was 38\%; 36\% of these had used in the past 4 weeks (active use). CD use was higher in MSM than heterosexuals, in heterosexual males than females, and in those $<25$ years.

Self-perceived risky sex was higher in MSM than heterosexuals using mephedrone (OR4.38 $\mathrm{p}=<0.0001$ ), ecstasy, GHB and ketamine. MSM reported more difficulty in controlling their drug use (OR1.6, $\mathrm{p}=0.02)$.

Lack of condom use in the past 12 months in heterosexual $\mathrm{CD}$ users and non-users was the same, but $\mathrm{CD}$ users were more likely to have $\geq 3$ partners (OR2.3 $\mathrm{p}=0.0001)$. Heterosexual $\mathrm{CD}$ active users were more likely to have had anal sex in the past 4 weeks (OR2.6, p $=0.0001)$; recent heterosexual anal sex was associated with chlamydia (OR2.41, $\mathrm{p}=0.0007)$.

There were no associations between lifetime or active use of $\mathrm{CD}$ and STI prevalence in heterosexuals (lifetime OR0.91, p = 0.54; active OR1.02, $\mathrm{p}=0.94$ ) or MSM (lifetime OR1.30, $\mathrm{p}=$ 0.35 ; active OR1.21, $\mathrm{p}=0.63$ ).

Conclusion This is the first sexual health clinic study in the UK to assess CD use in all sexualities. Lifetime use of CD was high. $\mathrm{CD}$ use in heterosexuals was associated with higher risk sex but lifetime or recent $\mathrm{CD}$ was not associated with a higher prevalence of STIs. STI acquisition is multifactorial and is not solely determined by CD use.

Disclosure of interest statement No disclosures of interest.

\section{P13.11 SELF-TAKEN EXTRAGENITAL SAMPLING FOR CHLAMYDIA AND GONORRHOEA IN WOMEN - IS IT ACCEPTABLE? FEEDBACK FROM A SELF-SWAB AND CLINICIAN-SWAB TRIAL}

HE Wallace, J Fisher, S Daley, R Harrison, JD Wilson*. Leeds Centre for Sexual Health, Leeds Teaching Hospitals NHS Trust, UK

\subsection{6/sextrans-2015-052270.509}

Introduction Self-taken vulvovaginal swabs analysed by nucleic acid amplification tests (NAATs) for chlamydia and gonorrhoea are standard practice worldwide. Extra-genital sampling (rectum and pharynx) is becoming increasingly important in women, with evidence that urogenital sampling alone may miss infections. Yet, little is known about women's views of extra-genital sampling. We explored the acceptability of self-taken extra-genital samples for women as part of a clinician versus self-taken extra-genital sampling study.

Methods Women attending a sexual health clinic were invited to participate in a 'swab yourself' trial. After randomisation, both clinician and self-taken samples for chlamydia and gonorrhoea NAATs from vulvovaginal, pharyngeal and rectal sites were taken. Participants were then invited to complete a questionnaire about the extra-genital sampling. 